\title{
SPATIOTEMPORAL MODELING FOR ASSESSING COMPLEMENTARITY OF RENEWABLE ENERGY SOURCES IN DISTRIBUTED ENERGY SYSTEMS
}

\author{
L. Ramirez Camargo a,b *, R. Zink ${ }^{a}$, W. Dorner ${ }^{a}$ \\ a Applied Energy Research Group, Technologie Campus Freyung, Deggendorf Institute of Technology, Germany - \\ (luis.ramirez-camargo, wolfgang.dorner, roland.zink)@th-deg.de \\ b Institute of Spatial Planning and Rural Development, University of Natural Resources and life Sciences, Vienna, Austria
}

\begin{abstract}
KEY WORDS: Integrated Spatial and Energy Planning, Energy Balance Time Series, Renewable Energy Sources, Virtual Power Plants, Spatiotemporal Modeling, GRASS GIS, Python
\end{abstract}

\begin{abstract}
:
Spatial assessments of the potential of renewable energy sources (RES) have become a valuable information basis for policy and decision-making. These studies, however, do not explicitly consider the variability in time of RES such as solar energy or wind. Until now, the focus is usually given to economic profitability based on yearly balances, which do not allow a comprehensive examination of RES-technologies complementarity. Incrementing temporal resolution of energy output estimation will permit to plan the aggregation of a diverse pool of RES plants i.e., to conceive a system as a virtual power plant (VPP). This paper presents a spatiotemporal analysis methodology to estimate RES potential of municipalities. The methodology relies on a combination of open source geographic information systems (GIS) processing tools and the in-memory array processing environment of Python and NumPy. Beyond the typical identification of suitable locations to build power plants, it is possible to define which of them are the best for a balanced local energy supply. A case study of a municipality, using spatial data with one square meter resolution and one hour temporal resolution, shows strong complementarity of photovoltaic and wind power. Furthermore, it is shown that a detailed deployment strategy of potential suitable locations for RES, calculated with modest computational requirements, can support municipalities to develop VPPs and improve security of supply.
\end{abstract}

\section{INTRODUCTION}

Independence from fossil fuel import and climate change mitigation are some of the main arguments for adopting renewable energy sources (RES) and for transforming our current centralized energy supply system into a distributed one. There are, however, two major challenges for adopting RES, such as wind and solar radiation, as the main energy supply source: First, RES are spread on the planet in relatively low concentrations (Stoeglehner et al., 2011). Second, the availability of most abundant RES is variable on time and these are also nondispatchable (Widén et al., 2015). Although these two concerns are strongly related, the existent tools for planning energy supply systems based on RES attempt to deal with them separately. On the one hand, geographic information systems (GIS) are well stablished tools to determine potential locations for the deployment of RES based on multiple ecological, regulative and mostly on resources availability criteria (Angelis-Dimakis et al., 2011). The latest is still the main factor for determining the profitability of individual installations. On the other hand, established tools for sizing RES based energy systems considering the temporal variability such as; HOMER, the BCHP Screening Tool, HYGROGEMS and TRNSYS16, focus on stand-alone applications for single buildings, local communities, or single project applications (Connolly et al., 2010; Mendes et al., 2011). Additionally, there are models such as EnergyPLAN and $\mathrm{H}_{2}$ RES, that are designed to optimise energy systems to accommodate the fluctuations of RES and perform the analysis in temporal resolutions of up to one hour time steps (Connolly et al., 2010). These work in a technology type aggregated level that neglects the differences in the output of the same technology located elsewhere in the modelled system. Therefore, system sizes can be determined for each technology but it is not possible to determine where to locate individual installations unless these are modelled as different technologies. Attempting to do this for thousands of potential installations of the same technology, but in different locations would become highly time consuming and impracticable.

Not to mention that the RES decision support and mapping exercises are usually provided by international, national or state/provincial agencies while the decisions about RES deployment must in fact be taken at the municipal and regional scale, where there is often a lack of funding and human resources for performing these tasks directly (Calvert et al., 2013). A good example to overcome this last limitation are the energy use plans for municipalities supported by the state of Bavaria in Germany. These are financed by the state government but are developed by research institutions in strong interaction with the municipalities. There is also an official guide for developing energy use plans for municipalities supported on GIS (Bayerisches Staatsministerium für Umwelt und Gesundheit et al., 2011). These, however, have the same bias of most GIS based procedures and are only intended for calculating total yearly potentials and finding suitable locations for RES deployment. The consequence of using a merely spatial approach is that no recommendation can be given about adequate share of RES for the local system. Extending GIS-based analysis in the temporal dimension will allow to perform these tasks and to propose municipality wide system configurations such as virtual power plants (VPPs). In the European context VPP refers to a diverse pool of RES aggregated to supply a certain demand with a reliability level comparable to traditional fossil based power plants (Asmus, 2010).

The problem that arises when trying to conduct spatiotemporal analysis on GIS platforms is that they are disk-I/O-reliant and are usually not conceived for parallel processing. These characteristics make traditional GIS tools too slow to handle the massive amounts of data that are generated when modeling

\footnotetext{
* Corresponding author.
} 
resources availability in a high spatiotemporal resolution. Bryan (2013) showed that without relying on proprietary software (that is conceived for optimized parallel computing) and/or large computer clusters it is possible to handle models with massive amounts of spatial data. He achieved substantial performance enhancement by migrating the processing of one test model from a GIS platform to the in-memory array processing environment of Python and Numpy (Bryan, 2013). Moreover, nowadays model performance improvement is widely available due to the existence of open source tools and low cost hardware options such as multi-core processors, grid computing, cloud computing, and graphics processing units (GPUs) with thousands of computing units accessible even for personal computers (see e.g., Fernández-Quiruelas et al., 2011; Tabik et al., 2012).

This paper presents a spatiotemporal analysis methodology that couples GIS-based procedures for determining potential locations for wind and photovoltaic power plants with the analysis of the temporal variability of these RES. This methodology is adjusted to the German context. It is intended to deliver results in such a high resolution that allow for an early stage planning of the supply infrastructure necessary to integrate high shares of wind and PV in the energy matrix of municipalities in the form of a municipality wide VPP. The methodology should also serve to evaluate the complementarity of the energy produced by photovoltaic and wind power from a technical point of view in areas that do not allow major spatial dispersion. Furthermore, the methodology relies on open source tools and can be run with low cost computational infrastructure. The intention behind these last characteristics is that municipality energy advisors can replicate it without incurring costs (in terms of hardware requirements) beyond of the ones that would be necessary to perform a GIS-based spatial analysis of RES availability.

\section{METHODOLOGY}

The methodology consists of five subsequent steps (see Figure 1). First, a GIS-based workflow reduces the study area to the location of the potential RES-based energy generation plants. Second, a GIS-based procedure serves to gain the time series of available solar radiation and wind resources for every potential location. Third, an in-memory array process is used to calculate energy yield of every single potential power plant in a high temporal resolution. Fourth, a decision tree selects the most appropriate plants to cover a certain demand. Fifth, the resulting solution sets of power plants are evaluated using several indicators. All GIS related processes and calculations are performed with GRASS GIS 7 in a parallel implementation (when applicable) using Python (Oliphant, 2007) and all the further calculations rely on the in-memory array processing environment of Python and NumPy (van der Walt et al., 2011).

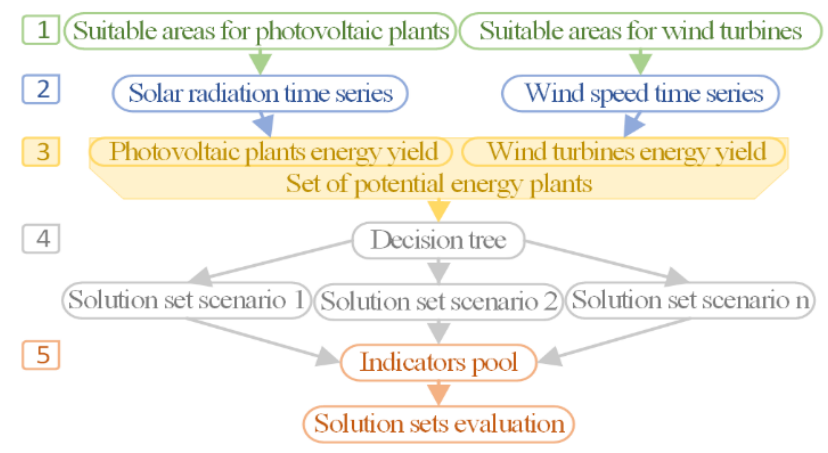

Figure 1. Overall workflow of the methodology
The starting points of the proposed methodology are the previous developments presented in Ramirez Camargo et al. (2015). These developments include; (1) a GIS-based procedure to estimate the potential PV electric power and energy generation time series of every roof-top section within a study area. (2) A peak-load mitigation strategy to define sets of PV plants based on the analysis of the energy output of the installation and the local demand. (3) A set of technical indicators to evaluate and compare the resulting PV sets. These are required for the present methodology but to avoid unnecessary repetitions only a brief description and applied improvements are described here in the corresponding sections.

\subsection{Selection of Potential Sites for RES Deployment}

The sum of the potential yearly solar radiation and the average wind speed are normally the main factors to identify suitable locations for the deployment of PV and wind power plants (Angelis-Dimakis et al., 2011). Our interest is, however, to account for variability in the availability of the resources and therefore we do not consider these simplified factors but the time series of resources availability in its best available resolution.

Additional factors, such as land use and legal constraints, are necessary to distinguish between relevant and irrelevant areas for the deployment of RES. The reduction from the whole area of the municipality to only feasible areas, for the construction of a certain RES-based power generation plant, strongly contributes to reduce complexity and computational time for the further analysis.

The selection of areas for wind power deployment follows the recommendations regarding the design and approval of wind turbines published by the Bayerischen Staatsministerium des Innern et al. (2011). The following locations are excluded: (1) Locations in a radius of $800 \mathrm{~m}$ from residential buildings, buildings on areas of especial use, buildings on mixed residential and commercial areas. (2) Locations in a radius of $500 \mathrm{~m}$ from industry buildings, air traffic areas, national parks, landscape conservation areas, bird protection areas, biotops and flora and fauna habitats. (3) Locations in a radius of $100 \mathrm{~m}$ from federal motorways (counting from the edge of the road), railways, power lines and federal, state and country roads.

Compared to the requirements for wind power plants the selection of suitable areas for photovoltaic installations is quite straightforward. The best possible locations for photovoltaic installations are roof-tops. When using these areas there is no conflict with other resources or uses. Nevertheless, it is not possible to take advantage of the whole surface of every roof and objects such as chimneys and dormers have to be excluded of the analysis. The remaining areas are classified depending on orientation (aspect) and inclination (slope) since these are two important factors that make a difference for the output of PV installations (Lang et al., 2015).

\subsection{Resources Time Series}

2.2.1 Wind Speed Time Series: The time series of wind speed for every location are calculated using the power law of logarithmic profiles for estimating wind speed at hub height from measurements at lower heights presented in equation 1 (see e.g., Hoogwijk et al., 2004 or Gass et al., 2011).

$$
V_{\text {hub }}=V_{m e s}\left(\frac{\ln \left(h_{h u b} / z\right)}{\ln \left(h_{m e s} / z\right)}\right)
$$


Where

$$
\begin{aligned}
& V_{\text {hub }}=\text { wind speed at hub height } \\
& V_{\text {mes }}=\text { wind speed at measurement height } \\
& h_{\text {hub }}=\text { hub height } \\
& h_{\text {mes }}=\text { height of the measurement facility } \\
& z=\text { surface roughness length }
\end{aligned}
$$

This equation only allows a plausible approximation for wind speeds below $80 \mathrm{~m}$ height, which is the upper boundary of the wind surface layer (Emeis, 2013). Consequently, if the reference wind speed is measured in the wind boundary layer (typical case for measurements for meteorological stations) only middle size turbines up to $80 \mathrm{~m}$ height can be modeled.

The parameter roughness length i.e., the distance above ground where the wind speed theoretically should be zero (Şen, 2013) changes depending on the land use and type of vegetation. This can be calculated using land use data for the study area, and estimations of the roughness length for different types of land use (see e.g., Silva et al., 2007).

The land use information is extracted from the land use map for every potential wind site identified following the procedure described in section 2.1. These values are compared with the roughness length estimation data. Finally the wind speeds at hub height for every potential area are calculated with equation 1 and stored in form of Numpy structured arrays.

2.2.2 Solar Radiation Time Series: Instantaneous solar radiation is calculated for every single roof-top area identified in 2.1 for every desired time step in a year using the modules r.horizon and r.sun of GRASS GIS, developed by Šúri and Hofierka (2004) and following the procedure presented by Ramirez Camargo et al. (2015). The horizons on the roof-top surfaces from near objects are pre-calculated with module r.horizon using a digital surface model (DSM) of the highest available resolution. Horizons from larger objects are calculated with a DSM of a coarser resolution. Solar radiation under clearsky conditions and solar radiation under real-sky conditions (with inclusion of measured solar radiation data) are calculated only for the suitable roof-top areas. The obtained raster maps are managed with the temporal data framework of GRASS GIS 7 developed by Gebbert and Pebesma (2014). Differently to the procedure of Ramirez Camargo et al. (2015), the extraction of the solar radiation values from the global solar radiation raster maps for every time step is performed with the module v.rast.stats of GRASS GIS 7 and the values are directly moved to memory in form of a Numpy structured array. v.rast.stats was tested for several cases with different spatial and temporal resolutions. It was at least 24 times faster than PKtools (McInerney and Kempeneers, 2015), the tool suggested by the authors, when running in single and multicore implementations.

\subsection{Energy Yield Calculation}

2.3.1 Wind Energy Output: The wind power output of a single turbine in every time step is calculated using the turbine performance curve presented in equation 2 (Arslan, 2010).

$$
P_{\text {wind }}(V)=\left\{\begin{array}{cl}
0, & V_{\text {hub }}<V_{\text {in }} \\
\frac{1}{2} * C p * \rho * V_{\text {hub }}{ }^{3} * \pi *\left(\frac{D}{2}\right)^{2}, & V_{\text {in }} \leq V_{\text {hub }}<V_{r} \\
P_{r_{-} \text {wind }}, & V_{r} \leq V_{\text {hub }}<V_{\text {out }} \\
0, & V_{\text {hub }} \geq V_{\text {out }}
\end{array}\right.
$$

Where

$$
\begin{aligned}
& P_{\text {wind }}=\text { actual power output of the turbine } \\
& C p=\text { capacity factor } \\
& V_{\text {in }}=\text { cut-in wind speed }
\end{aligned}
$$

$$
\begin{aligned}
& V_{r}=\text { rated wind speed } \\
& V_{\text {out }}=\text { cut-out wind speed } \\
& D=\text { diameter of the rotor } \\
& P_{r_{-} \text {wind }}=\text { rated power output } \\
& \rho=\text { the air mass density. }
\end{aligned}
$$

A distance of five times the rotor diameter between turbines is used to calculate the number of wind power installations that can be accommodated in a certain potential area. This is an usual value for existent wind parks (Samorani, 2013). Every potential area is divided in areas of $(5 * D)^{2}$ size. Since the number must be an integer and turbines can also be accommodated in the border of the potential area, the resulting number of installations is rounded to next larger integer number.

A time series of energy output is calculated for every wind turbine that fits in the potential area determined using the procedure in section 2.1. These time series are kept in form of a Numpy structured array. The underlying assumption for calculating the energy output is that the conditions given when calculating the power output remain constant during the length of every time step.

2.3.2 Photovoltaic Energy Output: the photovoltaic power output is calculated following equation 3. This equation was adapted by Ramirez Camargo et al. (2015) from the set of equations for calculating photovoltaic yield proposed by Jakubiec and Reinhart (2013).

$P_{P V}(G)=G * \eta_{P V} *\left[1+\alpha_{P M P P}\left(\left(T^{a m b}+k_{T} G / A\right)-T_{0}\right)\right]$

Where

$$
\begin{aligned}
& P_{P V}=\text { photovoltaic power output } \\
& G=\text { global irradiance } \\
& \eta_{P V}=\text { photovoltaic panel efficiency } \\
& \alpha_{P M P P}=\text { temperature correction factor } \\
& T^{a m b}=\text { ambient air temperature } \\
& k_{T}=\text { reduction factor due to installation type } \\
& A=\text { PV plant area } \\
& T_{0}=\text { nominal operating temperature. }
\end{aligned}
$$

To calculate the energy output the ambient temperature and global irradiance are assumed to be constant during every time step. The time series of PV energy output for every potential rooftop area are also kept in form of a Numpy structured array.

\subsection{Decision Tree for Constituting Municipality Wide RES- Based Energy Systems Configurations}

Beyond the usual analysis that suggests the most suitable power plants based on the yearly yield, we use a decision tree that selects plants based on the match of its power output time series to the time series of the local demand. The criterion for evaluating the match of the energy supply to the demand is ProperF as proposed by Ramirez Camargo et al. (2015) and presented in equation 4 . This criterion rates the power output of every plant based on the amount of properly supplied energy (equation 5) and the amount of excess energy (equation 6).

$$
\begin{aligned}
& \text { ProperF }=\left\{\begin{array}{l}
\frac{\sum_{t=1}^{T} \text { PrSu }_{t}}{\sum_{t=1}^{T} E x c_{t}} \text { if }\left(E x c_{t}>0\right) \\
\sum_{t=1}^{T} \operatorname{PrSu}_{t} \text { if }\left(E x c_{t}=0\right)
\end{array}\right. \\
& \operatorname{PrSu}_{t}=\left\{\begin{array}{l}
D_{t} \text { if }\left(E_{t} \geq D_{t}\right) \\
E_{t} \text { if }\left(E_{t}<D_{t}\right)
\end{array}\right.
\end{aligned}
$$




$$
E x c_{t}=\left\{\begin{array}{c}
E_{t}-D_{t} \text { if }\left(E_{t}>D_{t}\right) \\
0 \quad \text { if }\left(E_{t} \leq D_{t}\right)
\end{array}\right.
$$

Where $E x c_{t}=$ amount of excess energy in the time step $\mathrm{t}$ $D_{t}=$ local electric energy demand at the time step $\mathrm{t}$ $E_{t}=$ energy output of the power plant (wind or PV) in the time step $\mathrm{t}$

$\operatorname{PrSu}_{t}=$ amount of proper supplied demand in the time step $\mathrm{t}$

In a first step ProperF is calculated for all potential power plants. The power plant with the highest Proper $F$ is selected and its energy output is discounted from the local energy demand time series. In the next step the energy output of the remaining plants is evaluated with ProperF against the new demand. A further installation is selected. The selection process continues until the sum of the energy output of the plants equals a desired share of the total yearly demand of the studied municipality. This procedure is not amenable for parallelization. However, the implementation in Python and Numpy allows the efficient handling of the energy output data from several thousands of power plants and temporal resolutions up to quarter hours with state of the art hardware for usual GIS processing.

\subsection{Indicators for Evaluation of the System Configurations}

To evaluate the contribution of a certain system configuration to the local energy balance a series of indicators are proposed; (1) Total installed capacity (in $\mathrm{kW}$ ). It is the sum of the required installed capacity of PV and/or wind power, which is required to cover a certain desired share of the total yearly demand. (2)

Variability of the output (in $\mathrm{kW}$ ). It serves to evaluate how high the average variation between time steps in the output of a system configuration is. This indicator also serves to have an idea of how much back-up power capacity would be required to provide a stable supply. Variability is defined as presented by Hoff and Perez (2012). (3) Total unfulfilled demand (in MWh). It is the sum of the energy demand that cannot be covered by the evaluated power plants solution set. (4) Total excess energy (in $\mathrm{MWh}$. This indicator is the sum for all time steps of the value defined in equation 6. (5) Total properly supplied energy (in $\mathrm{MWh})$. It is the sum for all time steps of the value defined in equation 5. (6) The loss of power supply probability (LPSP). It is used for evaluating the reliability of the energy systems configuration. Its definition can be found in Yang et al. (2003). (7) Hours of supply higher than the highest demand. It serves to quantify the number of moderately high energy generation peaks. (8) Hours of supply higher than 1.5 times the highest demand. This indicator shows the number of high energy generation peaks. (9) Storage required energy capacity (MWh). This indicator provides information about the size of the storage system that must be installed in order to store the totality of the produced energy by a certain system configuration. It is calculated following the algorithm developed by Solomon et al. (2010). We assume that the only energy loss is due to storage inefficiencies (the usually assumed efficiency for storage is systems is $75 \%$ ) and that all the energy generated by the power plants solution set is accepted regardless of the back-up capacity that would be necessary to ensure security of supply. (10) Storage required power capacity. This indicator can be calculated following the same algorithm as for the previous indicator. It represents the maximum amount of excess power that must be stored in a certain time step during the studied period.

\section{CASE STUDY}

The data from Waldthurn, a rural municipality located in northeast Bavaria (Germany), was used to test the proposed methodology. The total area of this municipality comprises 30.97 $\mathrm{Km}^{2}$. It is characterized by a very diverse topography; with terrain elevations above the sea level ranging from 480 to $800 \mathrm{~m}$. Waldthurn has 2,019 inhabitants and a total of 2,518 buildings divided in 650 main buildings (e.g., one family houses, multiple family houses or business) and 1,868 secondary buildings (e.g., stables, garages or tools deposits). The Bavarian Surveying Agency (2014) provided the Vector data with the built-up areas and use classification of the buildings and infrastructure, land use data, soil classification data, and LiDAR data with a density of at least 4 points per square meter in 32 tiles of $1 \mathrm{~km}^{2}$. Only the tiles where buildings were located were considered for creating a DSM with a pixel resolution of $1 \mathrm{~m}^{2}$ (DSM1). The DSM1 was generated according to the procedure described by Neteler and Mitasova (2008). To calculate the horizon on the roof-surfaces generated by distant large objects as hills and mountains, we used the freely available DSM25 of the European Union from the GMES RDA project (EU-DEM).

Concerning wind power potential, only 9 of the 14 criteria for defining the suitable areas were pertinent due to the lack of air traffic areas, flora and fauna habitats, bird protection areas, national parks and railways in the municipality. The Surface roughness length was determined using the land use data and the surface roughness classification presented by Silva et al. (2007).

The roof-top surfaces for potential photovoltaic power plants were defined using the vector layer of the build-up areas, the DSM1 and its derived slope and aspect maps. The roof-top areas were extracted from the DSM1, aspect and slope maps using the vector layer and the resulting maps were compiled in an image group. This image group was the input for an unsupervised classification to divide the roof-tops parts in four different categories. The classification was performed with the i.cluster and i.maxlik modules of GRASS GIS 7. The resulting raster layer was smoothed with the r.neighbors module in GRASS GIS 7 and the new raster map was transformed into a vector map where the potentially usable roof-top areas were divided in four homogeneous groups. These groups describe surfaces oriented in cardinal directions that range from: (1) north to east, (2) east to south, (3) south to west and (4) west to north. In a last step, all surfaces smaller than $15 \mathrm{~m}^{2}$ were removed to avoid considering roof objects unsuitable for PV installations such as chimneys and dormers.

The total electric energy demand of the municipality divided by households, commercial buildings, heat pumps, public institutions, street lighting and agriculture for 2012 was obtained from the final report of the current energy use plan of the municipality. Bayernwerk, the local grid operator, provided the measured data presented in that report. To disaggregate the yearly totals in hourly time steps the standardized load profiles provided by the BDEW (Bundesverband der Energie- und Wasserwirtschaft) are used. These data sets consider the daily and seasonal variations of the demand profiles of 11 different types of users in 15 minutes time steps. The 7 users reported in the energy use plan of the municipality were summarized in 5 of the users types of the standardized load profiles, namely; households, agriculture in general, commerce in general, commerce on week days from 8 am to $6 \mathrm{pm}$ and street lightning. It is assumed that all consumers are part of the same grid. The resulting time series for households are expected to be reliable (deviations around $+/-10 \%$ ) because the number of considered 
residential buildings is above 400 (Esslinger and Witzmann, 2012). The time series in 15 minutes time steps are aggregated into hours to fit the temporal resolution of the weather data.

The input weather data obtained from a neighbouring weather station coincide with the geographic characteristics of the areas for potential power plants and the year of the available demand data of the study area. The data includes global solar radiation, ambient temperature and wind speed for the year 2012. These were retrieved from the Bavarian agrometeorological service (Bayerische Landesanstalt für Landwirtschaft 2014), from the nearest one of 132 available stations. Although there were three stations within a distance of $17 \mathrm{~km}$ from the centre of the municipality (Almesbach, Söllitz and Konnersreuth), the selected station (Söllitz)was preferred because it is located $550 \mathrm{~m}$ above the sea level, which is comparable to the average altitude of the areas of the case study municipality with potential locations for photovoltaic and wind power plants. The global solar radiation was divided into its direct and diffuse parts using the algorithm based on the clearness index and the solar altitude proposed by Reindl et al. (1990).

For the estimation of the potential energy output of the installations we used data of an average monocrystalline silicon cell PV module and a Vestas V29 wind turbine. The technical characteristics of these plants are presented in table 1 .

\begin{tabular}{|c|c|c|c|}
\hline & Parameter & Value & Units \\
\hline \multirow{6}{*}{ 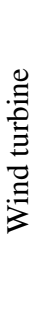 } & Rated power output & 225 & $\mathrm{~kW}$ \\
\hline & Rated wind speed & 16 & $\mathrm{~m} / \mathrm{s}$ \\
\hline & Cut-in wind speed & 3.5 & $\mathrm{~m} / \mathrm{s}$ \\
\hline & Cut-out wind speed & 25 & $\mathrm{~m} / \mathrm{s}$ \\
\hline & Rotor diameter & 29 & $\mathrm{~m}$ \\
\hline & Hub height & 31 & $\mathrm{~m}$ \\
\hline \multirow{4}{*}{$\begin{array}{l}\bar{\Phi} \\
\stackrel{\Xi}{ \pm} \\
\stackrel{1}{a} \\
\text { a }\end{array}$} & Panel efficiency & 14.4 & $\%$ \\
\hline & Temperature correction factor & -0.0045 & $\% / \mathrm{K}$ \\
\hline & $\begin{array}{l}\text { Reduction factor due to } \\
\text { installation type }\end{array}$ & 0.035 & $\mathrm{~K} /\left(\mathrm{W} / \mathrm{m}^{2}\right)$ \\
\hline & inverter and cable losses & 14 & $\%$ \\
\hline
\end{tabular}

Table 1. Technical parameters of the photovoltaic plants and wind turbines

The selected wind power plant technology has a total height of $44.5 \mathrm{~m}$, which under German regulation do not require the strict pollution control authorization that is mandatory for wind turbines with a total height above $50 \mathrm{~m}$ (Bayerischen Staatsministerium des Innern et al., 2011). This reduced size also means that the proposed potential plants will be less profitable than state of the art installations with a total height beyond 100 $\mathrm{m}$ (when considering only the total amount of energy generated). Nevertheless, under the current German and Bavarian regulations these turbines with less than $50 \mathrm{~m}$ height have much more chances of being actually build.

Only-PV, only-wind and combined PV-wind supply system configurations that achieve penetration levels of $25 \%, 50 \%, 75 \%$ and $100 \%$ in terms of the total yearly demand as well as systems configurations that do not allow any energy dumping during the year were calculated. The only-PV and only-wind solutions sets for the different penetration levels correspond to a solely spatial analysis where plants are selected based on the maximum yearly production. The combined PV-Wind for all penetration levels and the no-dump system configurations were calculated using the proposed decision tree. Finally, the solutions sets were evaluated with the proposed indicators.

The methodology for this case study was run in a 64bit AMD LINUX workstation with an Intel Xeon E5-1620 v2 CPU of four physical cores and 16GB of RAM. The employed software includes the first stable release of GRASS GIS 7, Python 2.7.5 and NumPy 1.8 .

\section{RESULTS AND DISCUSSION}

The potential maximum energy yield from PV is $25,244 \mathrm{MWh}$ obtained from the sum of the yearly yield of 4,118 considered potential installations. Four locations were found to be spatially suitable for wind power plants, these cover a total area of 254,199 $\mathrm{m}^{2}$ and can fit up to fourteen V29 wind turbines with a total yearly yield of 1,870 MWh. The total demand amounts 5,369 MWh and the accumulated values per hour for the whole year and for a random day in summer and a random day in winter are presented in Figure 2.

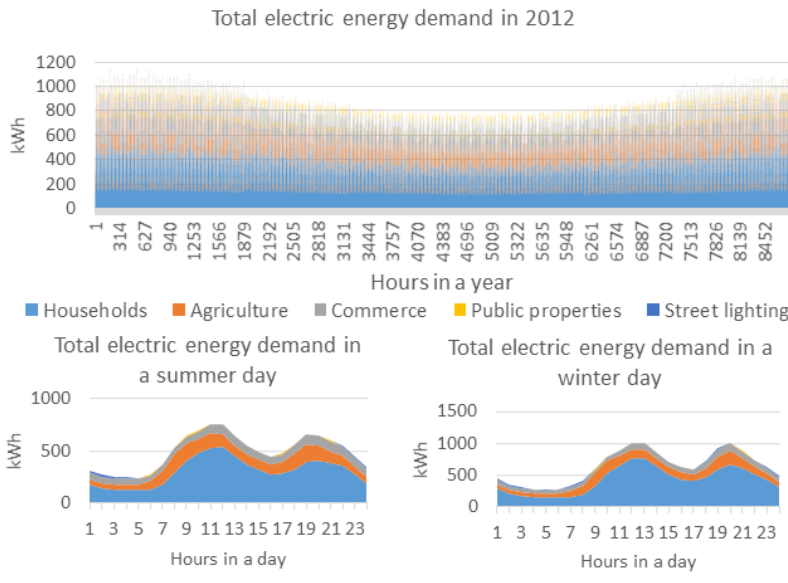

Figure 2. Cumulated energy demand of all user types in one hour time step for 2012

All indicators for the calculated system configurations are shown in Table 2. These present a strong contrast to the potential maximum yearly values. Although the total energy yield from PV installations is 3.7 times larger than the total yearly demand, in effect the only-PV solution set that should be able to produce as much energy as it is demanded in the whole year only achieves a LPSP of 0.701 and provides less than $50 \%$ of the energy when it is actually required. The only-PV configuration that does not allow any excess energy already shows that only a minimum part of the PV potential can be fully utilized ( 846 of 38,109 potential $\mathrm{kWp}$ installed capacity).

In contrast to the PV energy generation potential the wind energy potential represents only $35 \%$ of the total yearly demand. However, the results obtained with the spatiotemporal methodology for only-wind system configurations deliver (analogue to the case of only-PV system configurations) a completely different picture than the one provided when only considering the yearly sums. For the $25 \%$ penetration level, which is the only one that can be achieved with an only-wind system, the unfulfilled demand and the excess energy indicators are even worse than for the only-PV system configuration at the same penetration level. The amount of properly supplied energy only achieves $20 \%$ of the total energy demand and the only-wind no-dump system configuration utilizes only one of the fourteen 
potential power plants. The LPSP improves compared to the only-PV system configuration but the number of hours with the supply higher than the highest demand, the required storage energy and power capacities are much higher. This suggests that wind energy generation has a very variable profile, what is confirmed by the variability indicator that is $37 \%$ higher than for the only-PV system configuration.

The combined PV-wind system configurations, which are an important step towards planning municipality wide VPPs, provide improvements in most of the indicators when comparing against only-wind and only-PV system configurations. A comparison with the only-wind solution sets with a penetration rate beyond $35 \%$ is not possible, since this is the maximum wind power potential. However, it is not to expect that the indicators of the only-wind solutions could improve because it would require significant variations in the wind regime. These would be given only if we consider potential locations away from the study region. For the solution sets that can be compared the variability is lower in all cases for the combined PV and wind power solution set, but when the selected wind power installed capacity is notably higher than the selected PV installed capacity (PV\&Wind-50).

Moreover, the unfulfilled demand is always up to $20 \%$ lower for the PV and wind power solution sets. This is consistent with the amount of properly supplied energy, which is always higher for theses solution sets. Also the LPSP is better for higher penetration levels. For the 25\% penetration level the LPSP is better for the only-wind configuration due to the higher amount of generation peaks, which is not really a positive result for the only-wind solution set. The number of over generation peaks is always lower and in the case of the number hours when the supply is higher than 1.5 times the highest demand in a $75 \%$ penetration level, the combined PV and wind power solution presents $70 \%$ less hours than the only-PV solution set counterpart. Concerning the storage energy and power capacity required for storing all the excess energy, the only-PV solution sets rate better for the penetration levels $25 \%$ and $50 \%$, which is explained by the high amount of generation peaks introduced by the wind power in the other solution sets. Nevertheless, as soon as the share of wind and PV in the installed capacity starts to level up, the required storage energy capacity becomes lower for up to $140 \%$ for the combined PV and wind power solution sets. The major drawback of the combined PV and wind power solution sets is the increased required total installed capacity but is overcompensated in most of the cases by, among others, the increased amount of properly supplied energy.

Additionally, the relatively compact area of the municipality and the strong evidence of high complementarity between solar and wind power served to confirm the findings of Hoicka and Rowlands (2011) and Widen (2011). These authors stated that spatial dispersion is less important for the complementarity between wind and PV systems than for the smoothing of the output of only-PV or only-wind systems.

Finally, the results of the methodology can be visualized with a GIS platform. The spatial distribution and installation size of the combined PV and wind system configuration to produce as much energy as the total yearly demand is presented in Figure 3.

\begin{tabular}{|c|c|c|c|c|c|c|c|c|c|c|c|c|}
\hline $\begin{array}{l}\text { Technology- } \\
\text { Penetration level }\end{array}$ & 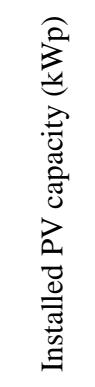 & 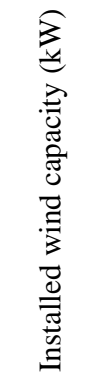 & 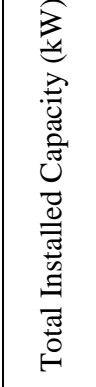 & 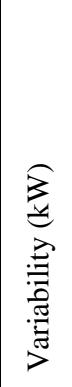 & $\begin{array}{l}\hat{\tilde{a}} \\
\text { ڤे }\end{array}$ & 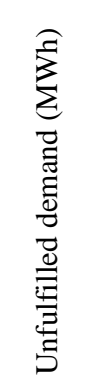 & 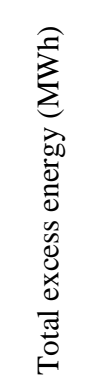 & 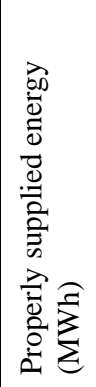 & 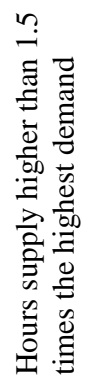 & 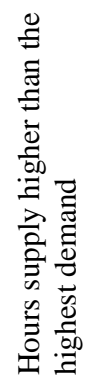 & 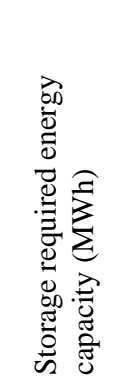 & 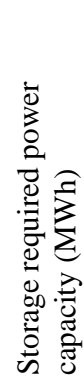 \\
\hline PV-noDump & 846 & - & 846 & 50 & 1 & 4.679 & - & 685 & - & - & - & - \\
\hline Wind-noDump & - & 225 & 225 & 21 & 1 & 5.145 & - & 219 & - & - & - & - \\
\hline PV\&Wind-noDump & 462 & 225 & 687 & 34 & 1 & 4,777 & - & 587 & - & - & - & - \\
\hline PV-25 & 1,654 & - & 1,654 & 98 & 0.95 & 4,108 & 75 & 1,257 & 0 & 39 & 2.867 & 0.402 \\
\hline PV-50 & 3,357 & - & 3,357 & 196 & 0.836 & 3,452 & 766 & 1,913 & 257 & 741 & 11.435 & 1.439 \\
\hline PV-75 & 5,086 & - & 5,086 & 292 & 0.757 & 3,109 & 1.772 & 2,256 & 740 & 1294 & 126.399 & 2.473 \\
\hline PV-100 & 6,824 & - & 6,824 & 387 & 0.701 & 2,912 & 2.911 & 2,453 & 1070 & 1750 & 657.708 & 3.490 \\
\hline Wind-25 & - & 1.575 & 1,575 & 135 & 0.931 & 4,272 & 237 & 1,093 & 0 & 238 & 18.694 & 0.974 \\
\hline Wind-50 & - & 3.150 & 3,150 & 200 & 0.901 & 4,028 & 534 & 1,336 & 207 & 375 & 53.093 & 1.992 \\
\hline Wind-75 & - & 3.150 & 3,150 & 200 & 0.901 & 4,028 & 534 & 1,336 & 207 & 375 & 53.093 & 1.992 \\
\hline Wind-100 & - & 3.150 & 3,150 & 200 & 0.901 & 4,028 & 534 & 1,336 & 207 & 375 & 53.093 & 1.992 \\
\hline PV\&Wind-25 & 919 & 900 & 1,819 & 90 & 0.964 & 3,975 & 57 & 1,389 & 0 & 12 & 3.119 & 0.469 \\
\hline PV\&Wind-50 & 1,017 & 3.150 & 4,167 & 210 & 0.867 & 3,339 & 648 & 2,025 & 232 & 465 & 57.651 & 1.992 \\
\hline PV\&Wind-75 & 2,727 & 3.150 & 5,877 & 257 & 0.741 & 2,672 & 1.328 & 2,692 & 431 & 1099 & 65.182 & 2.582 \\
\hline PV\&Wind-100 & 4,445 & 3.150 & 7,595 & 328 & 0.661 & 2,384 & 2.390 & 2,981 & 977 & 1729 & 273.822 & 3.489 \\
\hline
\end{tabular}

Table 2. Indicators for all solution sets 


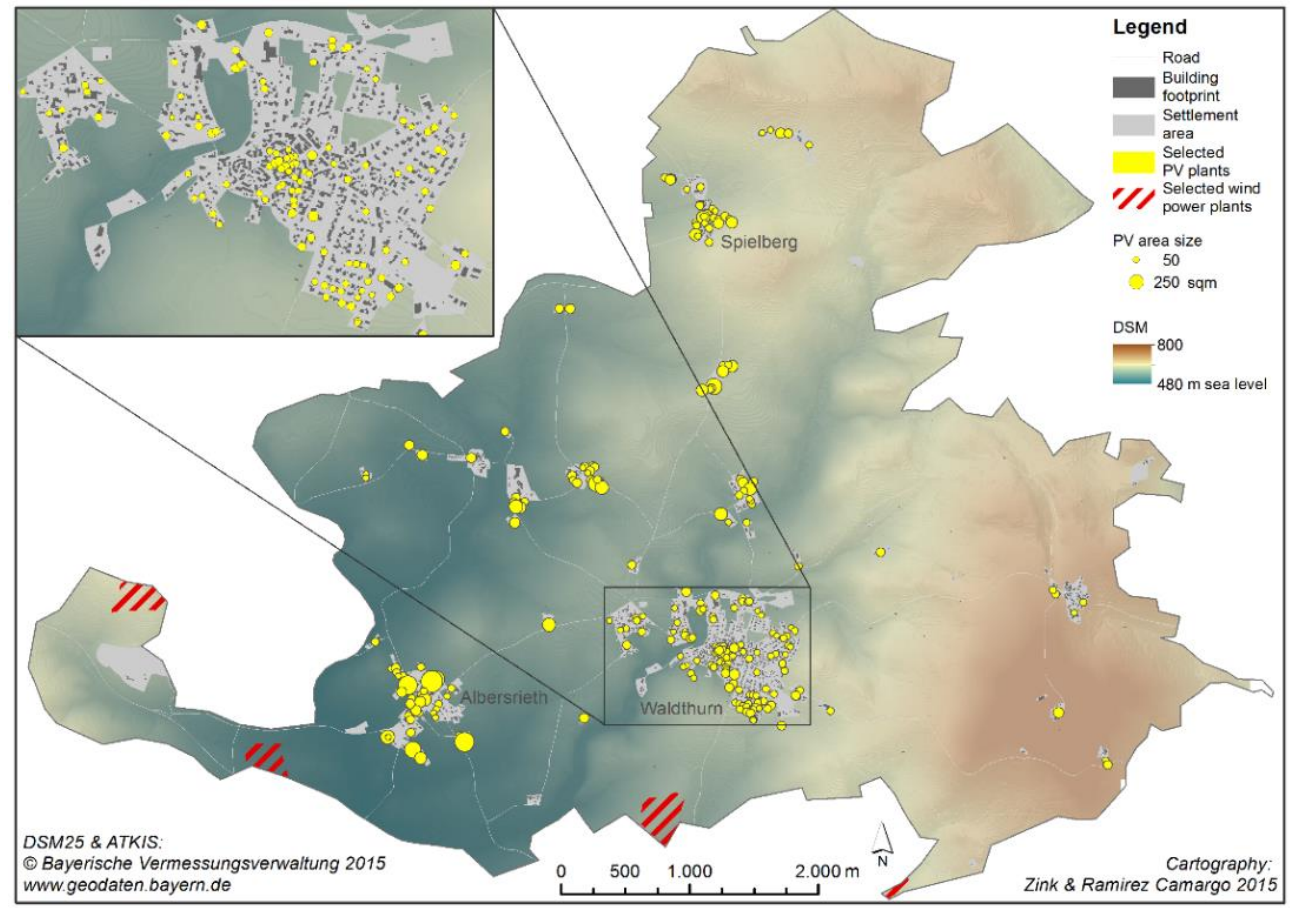

Figure 3. Selected PV and wind power plants with an electric energy output equal to the total yearly demand (PV\&Wind-100)

\section{CONCLUSIONS AND OUTLOOK}

The solely spatial analysis of RES availability is inadequate for providing any information about which technology should be preferred between PV and wind power or in which proportions they should be combined. The only information that can be obtained is the total amount of energy that could be produced in a year, and a classification of convenient locations based on its total yield. The spatiotemporal analysis goes beyond that, by simultaneously taking into account the spatial dispersion and the temporal variability of RES. This allows for the evaluation of complementarity between different RES, and the development of plans for conceiving a local distributed energy system as one single power plant, such as a virtual power plant.

This paper presented a methodology for spatiotemporal analysis of the potential of photovoltaic and wind power for entire municipalities in the German context, from a technical point of view. The implementation in open source processing tools facilitates its replicability. Furthermore, the combination of CPU parallelization for the GIS-based analysis and the use of the inmemory array processing environment of Python and Numpy allows to efficiently deal with massive amounts of data (compared with the merely spatial analysis), at low cost. The methodology was tested with data from the municipality of Waldthurn (Bavaria, Germany). The system configurations that combined Photovoltaic and wind power presented better results in the majority of the indicators than only-PV or only-wind system configurations. The results strongly support the idea of complementarity between PV and wind power. This even without wide geographical dispersion of the installations.

The presented methodology can be enhanced in several ways. For example; (1) The modeling periods can be extended to be equal to the life expectancy of the power generation installations (photovoltaic panels and wind turbines) and/or sensitivity analysis can be performed to improve the robustness of the results. (2) Reanalysis data can be used as data source for the wind speeds at hub height. (3) GPU parallel computing can be used for speeding up the GIS-based procedures (4) The decision tree approach can be replaced by an improved optimization algorithm. However, the methodology in its actual form already contributes to improve the information basis for decision-making concerning the deployment of RES at municipal scale beyond well established GIS-based procedures.

\section{ACKNOWLEDGEMENTS}

This research was developed in the project "Spatial Energy Manager" funded by the program "IngenieurNachwuchs des BMBF”, Germany (Grant number 03FH00712).

\section{REFERENCES}

Angelis-Dimakis, A., Biberacher, M., Dominguez, J., Fiorese, G., Gadocha, S., Gnansounou, E., Guariso, G., Kartalidis, A., Panichelli, L., Pinedo, I., Robba, M., 2011. Methods and tools to evaluate the availability of renewable energy sources. Renew. Sustain. Energy Rev., 15, pp. 1182-1200.

Asmus, P., 2010. Microgrids, Virtual Power Plants and Our Distributed Energy Future. Electr. J., 23, pp. 72-82.

Bavarian Surveying Agency, 2014. LiDAR data, vector maps with the built-up area and land use data from Waldthurn http://www.geodaten.bayern.de (11 Dec. 2013).

Bayerische Landesanstalt für Landwirtschaft, 2014. Agrarmeteorologie Bayern - www.wetter-by.de (13 June 2014 ).

Bayerischen Staatsministerium des Innern, Bayerischen Staatsministerium der Finanzen, Bayerischen Staatsministerium für Wirtschaft, Infrastruktur, Verkehr und Technologie, Bayerischen Staatsministerium für Umwelt und Gesundheit, Bayerischen Staatsministerium für Ernährung, Landwirtschaft und Forsten, 2011. Hinweise zur Planung und Genehmigung von Windkraftanlagen https://www.verkuendung-bayern.de/files/all 
mbl/2012/01/anhang/2129.1-UG-448-A001_PDFA.pdf (20 Apr. 2013).

Bayerisches Staatsministerium für Umwelt und Gesundheit, Bayerisches Staatsministerium für Wirtschaft, Infrastruktur, Verkehr und Technologie, Oberste Baubehörde im Bayerischen Staatsministerium des Innern, 2011. Leitfaden Energienutzungsplan http://www.stmi.bayern.de/imperia/md/ content/stmi/bauen/rechtundtechnikundbauplanung/_staedtebau/ veroeffentlichungen/oeko/leitfaden_enp.pdf (18 Apr. 12).

Bryan, B.A., 2013. High-performance computing tools for the integrated assessment and modelling of social-ecological systems. Environ. Model. Softw., 39, pp. 295-303.

Calvert, K., Pearce, J.M., Mabee, W.E., 2013. Toward renewable energy geo-information infrastructures: Applications of GIScience and remote sensing that build institutional capacity. Renew. Sustain. Energy Rev., 18, pp. 416-429.

Connolly, D., Lund, H., Mathiesen, B.V., Leahy, M., 2010. A review of computer tools for analysing the integration of renewable energy into various energy systems. Appl. Energy, 87, pp. 1059-1082.

Emeis, S., 2013. Vertical Profiles Over Flat Terrain. In: Wind Energy Meteorology, Green Energy and Technology. Springer Berlin Heidelberg, pp. 23-73.

Esslinger, P., Witzmann, R., 2012. Entwicklung und Verifikation eines Stochastischen Verbraucherlastmodells für Haushalte. Presented at the 12. Symposium Energieinnovation, Graz, Austria.

Fernández-Quiruelas, V., Fernández, J., Cofiño, A.S., Fita, L., Gutiérrez, J.M., 2011. Benefits and requirements of grid computing for climate applications. An example with the community atmospheric model. Environ. Model. Softw., 26(9), pp. 1057-1069.

Gass, V., Strauss, F., Schmidt, J., Schmid, E., 2011. Assessing the effect of wind power uncertainty on profitability. Renew. Sustain. Energy Rev., 15, pp. 2677-2683.

Gebbert, S., Pebesma, E., 2014. TGRASS: A temporal GIS for field based environmental modeling. Environ. Model. Softw., 53, pp. 1-12.

Hoff, T.E., Perez, R., 2012. Modeling PV fleet output variability. Sol. Energy, 86, pp. 2177-2189.

Hoicka, C.E., Rowlands, I.H., 2011. Solar and wind resource complementarity: Advancing options for renewable electricity integration in Ontario, Canada. Renew. Energy, 36, pp. 97-107.

Hoogwijk, M., de Vries, B., Turkenburg, W., 2004. Assessment of the global and regional geographical, technical and economic potential of onshore wind energy. Energy Econ., 26, pp. 889919.

Jakubiec, J.A., Reinhart, C.F., 2013. A method for predicting city-wide electricity gains from photovoltaic panels based on LiDAR and GIS data combined with hourly Daysim simulations. Sol. Energy, 93, pp. 127-143.

Lang, T., Gloerfeld, E., Girod, B., 2015. Don't just follow the sun - A global assessment of economic performance for residential building photovoltaics. Renew. Sustain. Energy Rev., 42, pp. 932-951.

McInerney, D., Kempeneers, P., 2015. Pktools. In: Open Source Geospatial Tools, Earth Systems Data and Models. Springer International Publishing, pp. 173-197.
Mendes, G., Ioakimidis, C., Ferrão, P., 2011. On the planning and analysis of Integrated Community Energy Systems: A review and survey of available tools. Renew. Sustain. Energy Rev., 15, pp. 4836-4854.

Neteler, M., Mitasova, H., 2008. Working with raster data. In: Neteler, M., Mitasova, H. (Eds.), Open Source GIS. Springer US, pp. 83-168.

Oliphant, T.E., 2007. Python for Scientific Computing. Comput. Sci. Eng., 9, pp. 10-20.

Ramirez Camargo, L., Zink, R., Dorner, W., Stöglehner, G., 2015. Spatio-temporal modeling of roof-top photovoltaic panels for improved technical potential assessment and electricity peak load offsetting at the municipal scale. Comput. Environ. Urban Syst., 52, pp. 58-69

Reindl, D.T., Beckman, W.A., Duffie, J.A., 1990. Diffuse fraction correlations. Sol. Energy, 45, pp. 1-7.

Samorani, M., 2013. The Wind Farm Layout Optimization Problem. In: Pardalos, P.M., Rebennack, S., Pereira, M.V.F., Iliadis, N.A., Pappu, V. (Eds.), Handbook of Wind Power Systems, Energy Systems. Springer Berlin Heidelberg, pp. 21-38.

Şen, Z., 2013. Innovative Wind Energy Models and Prediction Methodologies. In: Pardalos, P.M., Rebennack, S., Pereira, M.V.F., Iliadis, N.A., Pappu, V. (Eds.), Handbook of Wind Power Systems, Energy Systems. Springer Berlin Heidelberg, pp. 67-126.

Silva, J., Ribeiro, C., Guedes, R., 2007. Roughness length classification of Corine Land Cover classes, in: Proceedings of the European Wind Energy Conference, Milan, Italy., pp. 7-10.

Solomon, A.A., Faiman, D., Meron, G., 2010. Properties and uses of storage for enhancing the grid penetration of very large photovoltaic systems. Energy Policy, Special Section on Carbon Emissions and Carbon Management in Cities with Regular Papers, 38, pp. 5208-5222.

Stoeglehner, G., Niemetz, N., Kettl, K.-H., 2011. Spatial dimensions of sustainable energy systems: new visions for integrated spatial and energy planning. Energy Sustain. Soc., 1, pp. 1-9.

Šúri, M., Hofierka, J., 2004. A New GIS-based Solar Radiation Model and Its Application to Photovoltaic Assessments. Trans. GIS, 8, pp. 175-190.

Tabik, S., Villegas, A., Zapata, E.L., Romero, L.F., 2012. A Fast GIS-tool to Compute the Maximum Solar Energy on Very Large Terrains. Procedia Comput. Sci., 9, pp. 364-372.

Van der Walt, S., Colbert, S.C., Varoquaux, G., 2011. The NumPy Array: A Structure for Efficient Numerical Computation. Comput. Sci. Eng., 13, pp. 22-30.

Widen, J., 2011. Correlations Between Large-Scale Solar and Wind Power in a Future Scenario for Sweden. IEEE Trans. Sustain. Energy, 2, pp. 177-184.

Widén, J., Carpman, N., Castellucci, V., Lingfors, D., Olauson, J., Remouit, F., Bergkvist, M., Grabbe, M., Waters, R., 2015. Variability assessment and forecasting of renewables: A review for solar, wind, wave and tidal resources. Renew. Sustain. Energy Rev., 44, pp. 356-375.

Yang, H.X., Lu, L., Burnett, J., 2003. Weather data and probability analysis of hybrid photovoltaic-wind power generation systems in Hong Kong. Renew. Energy, 28, pp. 18131824. 